South African Journal of Geomatics, Vol. 5. No. 2, September 2016

\title{
Evaluating Spectral Indices for Winter Wheat Health Status Monitoring in Bloemfontein using Lsat 8 data
}

\author{
Zinhle Mashaba ${ }^{1,3}$, George Chirima ${ }^{1}$, Joel Botai ${ }^{2,3}$, Ludwig Combrinck ${ }^{4,3}$, \\ Cilence Munghemezulu ${ }^{3}$ \\ ${ }^{1}$ GeoInformatics Division, Agricultural Research Council, Pretoria, South Africa \\ ${ }^{2}$ South African Weather Services, Pretoria, South Africa \\ ${ }^{3}$ Centre for Geoinformation Science, Department of Geography, Geoinformatics and \\ Meteorology, University of Pretoria, Pretoria, South Africa \\ ${ }^{4}$ Hartebeesthoek Radio Astronomy Observatory, Krugersdorp, South Africa
}

Email: mashabaz@arc.agric.za, Tel: (+27) 0123102692

http://dx.doi.org/10.4314/sajg.v5i2.10

\begin{abstract}
Monitoring wheat growth under different weather and ecological conditions is vital for a reliable supply of wheat yield estimations. Remote sensing techniques have been applied in the agricultural sector for monitoring crop biophysical properties and predicting crop yields. This study explored the application of Land Surface Temperature (LST)-vegetation index relationships for winter wheat in order to determine indices that are sensitive to changes in the wheat health status. The indices were derived from Landsat 8 scenes over the wheat growing area across Bloemfontein, South Africa. The vegetation abundance indices evaluated were the Normalised Difference Vegetation Index (NDVI) and the Green Normalised Difference Vegetation Index (GNDVI). The moisture indices evaluated were the Normalised Difference Water Index (NDWI) and the Normalised Difference Moisture Index (NDMI). The results demonstrated that LST exhibited an opposing trend with the vegetation abundance indices and an analogous trend with the moisture indices. Furthermore, NDVI proved to be a better index for winter wheat abundance as compared to the GNDVI. The NDWI proved to be a better index for determining water stress in winter wheat as compared to the NDMI. These results indicate that NDVI and NDWI are very sensitive to LST. These indices can be comprehensive indicators for winter wheat health status. These pilot results prove that LST-vegetation index relationships can be used for agricultural applications with a high level of accuracy.
\end{abstract}




\section{Introduction}

Wheat is a staple food for most South Africans after maize, and thus, contributes significantly to the agricultural economy of the country (Meyer \& Kirsten, 2005). When the Wheat Board of South Africa was abolished in 1997, wheat markets were deregulated (Meyer \& Kirsten, 2005). Consequently, farmers diverted to other economically sustainable crops due to the ensued low profitability of wheat (Breitenbach \& Fényes, 2000). Furthermore, climate change and climate variability affected wheat production causing economic instabilities for farmers, especially those in rural communities who depend solely on rain-fed agriculture as their main source of sustenance (Tadross et al., 2005). Subsequently, wheat production declined in South Africa over the years (Breitenbach \& Fényes, 2000). The downward trend in production has necessitated monitoring the wheat health status.

Remote Sensing is an essential tool for estimating crop biophysical variables. Particularly, the Land Surface Temperature (LST)-vegetation index relationship, which is related to the canopy health (Huete et al., 1997). However, this relationship has been applied mainly for studying Urban Heat Islands, land use change, and urban expansion (Jiang \& Tian, 2010; Guo et al., 2012). Parida et al., (2008) reported that the MODIS derived Soil Moisture Index (SMI) computed from LST-Normalised Difference Vegetation Index (NDVI) relationships is linked to rice yields; low SMI values were associated with a decline in rice productivity. Johnson et al., (2014) linked corn and soybean yields to LST and NDVI for the Corn Belt region in the United States. The study documented that corn and soybean yields were positively correlated with NDVI, and had a negative correlation with daytime LST in the middle of summer. With the application of the LST-vegetation index relationship, water stress and vegetation abundance can be studied earlier during the growing season. This can help farmers modify their irrigation programs or applications of fertilisers, pesticides or herbicides to improve wheat growth at stressed areas. This approach can prevent or minimise crop losses and enhances agricultural productivity.

Classification methods and crop growth models are widely used for crop monitoring. These methods use remotely sensed satellite images to classify farmland into different classes (Ji-hua \& Bing-fang, 2008). Principally, supervised and unsupervised classification methods have been reliable for this purpose (Abuzar et al., 2000; Kuenzer \& Knauer, 2013). The approach can be used for the identification of farms, which have healthy or unhealthy crops. The main challenge of the above methods is discriminating pixels, which correspond to a certain crop type when there are mixed land uses (Löw \& Duveiller, 2014). Crop growth models are used to simulate the 
South African Journal of Geomatics, Vol. 5. No. 2, September 2016

biophysical processes, which take place in the soil, crop and atmosphere to understand the growth and development of a crop (Doraiswamy et al., 2004). Crop growth models are commonly linked with remote sensed data for crop monitoring applications (Moulin et al., 1998). The limitations of crop growth models are that they are less accurate when applied in non-optimal growing conditions. This limitation is breached by coupling crop growth models with remotely sensed data (i.e. Leaf Area Index (LAI)) to represent the actual growing conditions (Clevers \& van Leeuven, 1996). Crop models often require input data that might not be available for a particular site for example, solar radiation (Hoogenboom, 2000).

The aim of this research was to explore indices suitable for monitoring winter wheat health status based on the LST-vegetation index relationship. This application is important because numerous studies have focused on using the LST-NDVI relationship for monitoring global vegetation health or responses of vegetation to drought. However, these studies have not evaluated the performances of other spectral indices for such purposes (Kawabata et al., 2001; Julien et al., 2006; Raynolds et al., 2008; Julien et al., 2009; Karnieli et al., 2010; Swain et al., 2011; Son et al., 2012). Few studies have focused on using the LST-vegetation index relationship for a specific crop, for example Nemani et al., (1993). Thus, research questions addressed in this study are: can the LST-vegetation relationships be applied for wheat health status monitoring? Which spectral indices are best related to LST for wheat health status monitoring? Moisture indices and vegetation abundance indices derived for Landsat 8 were evaluated against LST. The index sensitive to winter wheat can then be applied in predicting wheat yields in advance before harvesting or even modifying farm management practices during the season for better yields at harvest.

The limitations of the study were that some of the Landsat 8 images were contaminated with cloud cover. Furthermore, because of crop rotations, some of the wheat farmers were not planting wheat at the same places consistently. This limited the samples and Landsat 8 images, which could be analysed. Although, this study could be extended with a longer time series, the Landsat 8 satellite was only launched recently, in 2013. Another challenge is that optical remote sensing is adversely affected by Precipitable Water Vapour (PWV) in the atmosphere, which can limit the amount of energy recorded by the optical sensor. Thus, reducing the contrast between the visible and near-infrared spectrum (Srivastava et al., 2014). This affects the potential of detecting optimal values for the derived parameters. Most studies do not correct for PWV (e.g., Julien \& Sobrino, 2009; Jiang \& Tian, 2010; Guo et al., 2012). This correction requires accurate determination of the PWV at the area of interest. Techniques such as Global Navigation Satellite Systems (GNSS) and Radiosondes can provide PWV parameters at millimeter accuracy (Combrink et al., 2007). However, the instrumentation involved 
South African Journal of Geomatics, Vol. 5. No. 2, September 2016

are costly to be directly applied to optical remote sensing unless a dedicated campaign is established. As the Trignet Network increases its density and the GNSS stations are collocated with meteorological stations, PWV values will be easily accessible to the general public (Hackl et al., 2011).

\subsection{Spectral Indices}

Spectral indices (Table 1) make it possible to model relationships between vegetation variables and reflectance data (Cohen et al., 2003). The Normalised Difference Vegetation Index (NDVI) is a commonly used spectral vegetation index. Through the use of NDVI, crop properties such as leaf biomass, canopy cover, chlorophyll content, nitrogen content, and leaf area are understood (Chavez \& Mackinnon, 1994, Gamon et al., 1995). The NDVI is best applied in sparse canopies as it loses its sensitivity in moderate to dense canopies (Gamon et al., 1995).

The Green Normalised Difference Vegetation Index (GNDVI) is a modified version of NDVI, which substitutes the green band in place of the red band in the NDVI equation. The GNDVI is sensitive to the chlorophyll concentration in vegetation when the leaf area index is moderately high. Therefore, GNDVI overcomes the problems with saturation, which NDVI exhibits for some vegetation types at later growth stages because it is more sensitive to low chlorophyll concentrations (Gitelson et al., 1996).

The Normalised Difference Water Index (NDWI) is a moisture index for determining vegetation water content (Jackson et al., 2004). The index is designed to enhance the reflectance

of water by using the green wavelengths, decreasing the low reflectance of NIR by water features and taking into account that vegetation and soil features have a high reflectance of NIR (McFeeters, 1996).

The Normalised Difference Moisture Index (NDMI) is correlated to the canopy water content and is an indicator of water stress (Hardisky et al., 1983). The NDMI uses the near infrared band, which is for the detection of reflectance of leaf chlorophyll content, and the mid-infrared band for the detection of the absorbance of leaf moisture (Wilson \& Sader, 2002). This index is not as 
widely applied due to the complexity of interpreting indices that use the mid-infrared band as compared to other indices, which use the red and near-infrared bands (McDonald et al., 1998).

Table 1. Landsat 8 derived spectral indices applied for wheat health status determination

\begin{tabular}{lll}
\hline Index & Equation & Reference \\
\hline Normalised & $N D V I=\frac{B 5-B 4}{B 5+B 4}$ & Elmore et al., (2000) \\
Difference & & \\
Vegetation Index & & Moges et al., (2004) \\
Green Normalised & $G N D V I=\frac{B 5-B 3}{B 5+B 3}$ & \\
Difference & \\
Vegetation Index & & \\
Normalised & $N D W I=\frac{B 3-B 6}{B 3+B 6}$ & Xu (2006) \\
Difference Water & & \\
Index & & Jin \& Sader (2005) \\
Normalised & $N D M=\frac{B 5-B 6}{B 5+B 6}$ & \\
Difference Moisture & & \\
Index & & \\
\hline
\end{tabular}

The LST-vegetation index space provides a comprehensive view of vegetation dynamics. There is a negative relationship between LST and vegetation indices (Nemani et al., 1993). This relationship can be applied to study the spatial variation of LST and vegetation indices for the determination of surface soil moisture or evapotranspiration (Julien \& Sobrino, 2009). This is done by deriving drought indices such as the Temperature Dryness Vegetation Index (TDVI) from the LST and NDVI feature space for drought monitoring applications (Sandholdt et al., 2002). The slope of the LST-NDVI is closely related to the evapotranspiration of a surface. Thus, an increase in evapotranspiration causes the soil moisture and NDVI to decline whereas, dense vegetation has more evapotranspiration and a lower LST (Prihodko \& Godward, 1997; Boegh et al., 1998). Additionally, the LST-vegetation relationship can be applied for vegetation monitoring (Julien and Sobrino, 2009). This is done by mapping the land cover and land use change patterns (Jiang \& Tian, 2010). 


\subsection{Study Area}

Bloemfontein covers an area of about $6300 \mathrm{~km}^{2}$ in the Free State province of South Africa (see Figure 1). The region is semi-arid and experiences summer rainfall from January to March with a mean annual precipitation of approximately $421 \mathrm{~mm}$ per annum. Temperatures are low in winter (minimum of $-5^{\circ} \mathrm{C}$ ) and high (maximum of $35^{\circ} \mathrm{C}$ ) in summer. The average altitude is less than $1200 \mathrm{~m}$ above sea level (Moeletsi, 2011). During the study period there were 50 farms, which had planted wheat. Of the 50 farms, 24 had planted wheat in the same area consistently for both years (2013 and 2014). A buffer of $2 \mathrm{~km}$ was applied to these 24 sample points to eliminate samples, which are close to each other, to obtain the final samples depicted in Figure 1.

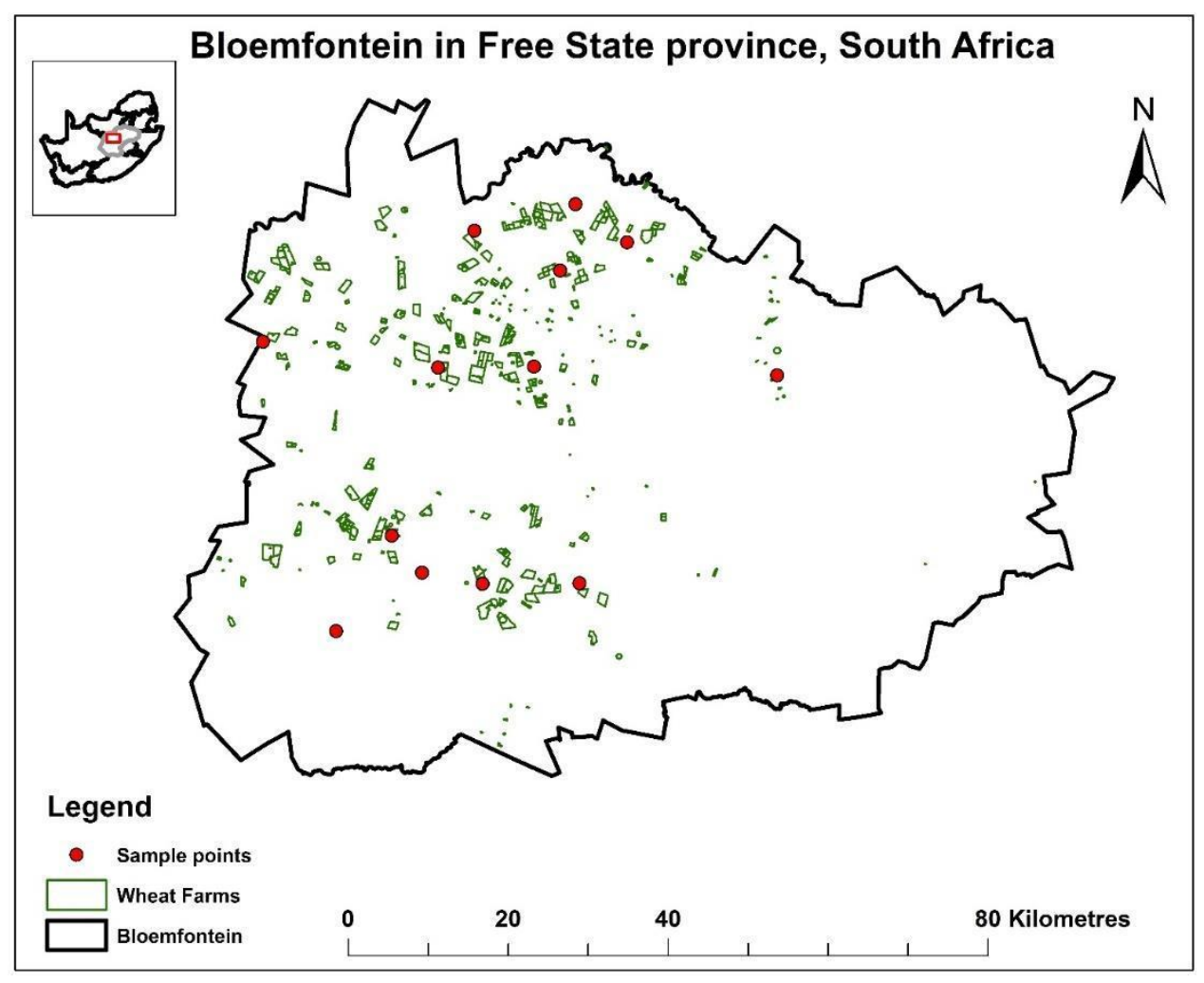

Figure 1. Location map of Bloemfontein within Free State Province. The sample points are illustrated by the red-dots and the wheat farms are represented by the green polygons 
South African Journal of Geomatics, Vol. 5. No. 2, September 2016

\section{Data and Methods}

\subsection{Data Acquisition and Data Pre-processing}

Landsat 8 scenes, depicted in Table 2 for Bloemfontein were acquired from the United States Geological Survey (USGS) site. Landsat 8 images for day of year 180 and 183 for both 2013 and 2014 were selected as wheat is at its greenest during this period.

Table 2. Landsat 8 scene for Bloemfontein selected for the study (http://earthexplorer.usgs.gov/)

\begin{tabular}{llllll}
\hline Path/row & DOY & Latitude & Longitude & $\begin{array}{l}\text { Sun elevation } \\
\left({ }^{\circ}\right)\end{array}$ & $\begin{array}{l}\text { Scene cloud } \\
\text { cover }(\%)\end{array}$ \\
\hline $171 / 80$ & 180 & -28.8691 & 26.22283 & 29.71951 & 0.03 \\
$171 / 80$ & 183 & -28.8691 & 26.22283 & 29.53000 & 2.63 \\
& & & & & \\
\hline
\end{tabular}

Landsat 8 images were preprocessed by doing radiometric calibration, for the conversion of digital numbers $(0-255)$ to radiances. The thermal bands, band 10 (thermal infrared 2) and band 11 (thermal infrared 2) of Landsat 8 were converted to Top of Atmosphere (TOA) spectral radiance for each of the bands using the Interactive Digital Language (IDL) according to:

$$
L_{\lambda}=M_{L} Q_{c a l}+A_{L}
$$

where, $L_{\lambda}$ is the TOA spectral radiance (Watts / $\left.\left(\mathrm{m}^{2 *} \mathrm{srad}^{*} \mu \mathrm{m}\right)\right), M_{L}$ is the multiplicative rescaling factor for band 10 and $11, Q_{c a l}$ is the quantised and calibrated standard product pixel values for band 10 and 11 and $A_{L}$ is the additive rescaling factor for band 10 and 11. The band multiplicative rescaling factor had a constant value of 0.0003342 and a constant additive rescaling factor of 0.1 according to the metadata file for both thermal bands. Atmospheric corrections were done using the Fast Line-of-sight Atmospheric Analysis of Spectral Hypercubes (FLAASH) in the ENVI software, this tool converts the radiance collected at the detector to radiance at the surface (Cooley et al., 2002). These images were used for the computation of Land Surface Temperature. 
Reflectances were computed from the Landsat 8 digital number images to radiometrically calibrate them for the derivation of spectral indices using IDL. The TOA planetary reflectance's were computed individually for bands 3 (green), 4 (red), 5 (near infrared) and 6 (short wave infrared 1) using:

$$
\rho_{\lambda}^{\prime}=M \underset{p}{Q} Q_{\text {cal }}+A_{p}
$$

In Equation [2], $\rho_{\lambda}$ ' is the TOA planetary reflectance, $M_{p}$ is the multiplicative rescaling factor for band 4, 5 and 11, $Q_{\text {cal }}$ quantised and calibrated standard product pixel values for band 4, 5 and $11,{ }_{p}^{A}$ is the additive rescaling factor for band 4,5 and 11 . Additionally, corrections for the Sun angle had to be made, according to:

$$
\rho_{\lambda}=\frac{\rho_{\lambda}^{\prime}}{\left(\sin \theta_{S E}\right)}
$$

where, $\rho \lambda$ is the TOA planetary reflectance with correction for Sun angle, $\rho \lambda^{\prime}$ is the TOA planetary reflectance and $\theta_{S E}$ is the Sun elevation angle.

\subsection{Computing the Land Surface Temperature and Vegetation Indices}

The TOA radiance images $(\mathrm{L} \lambda)$ were used to calculate the brightness temperature. However, both images had different values for the thermal conversion constants according to the metadata file, these were taken into account during the computation. The brightness temperature was calculated individually for both band 10 and band 11 according to:

$$
T_{B}=\frac{K_{2}}{\left(\frac{K_{1}}{L_{\lambda}}+1\right)}
$$


where, $K_{2}$ is the thermal conversion constant (band 10: 1321.08 and band 11: 1201.14), $K_{I}$ is the thermal conversion constant (band 10: 774.89 and band 11: 480.89) and $L_{\lambda}$ is the TOA spectral radiance (Watts / $\left(\mathrm{m}^{2 *} \mathrm{srad}^{*} \mu \mathrm{m}\right)$ ) (Artis \& Carnahan, 1982). Thereafter, the land surface temperature was computed for band 10 and band 11 separately using the brightness temperature images (Equation 5) according to Artis \& Carnahan (1982):

$$
T_{s}=\frac{T_{B}}{1+\left(\lambda T_{B} / \alpha\right) \ln \varepsilon}
$$

where, $\lambda$ is the wavelength of emitted radiance (11.5 $\times 10-6 \mathrm{~m}), \rho=h c / \delta, \quad h$ is Planck constant $\left(6.626 \times 10_{-34} \mathrm{Js}\right), c$ is the velocity of light $(2.998 \times 108 \mathrm{~m} / \mathrm{s}), \delta \quad$ is the Boltzmann constant $\left(1.38 \times 10_{-23} \mathrm{~J} / \mathrm{K}\right)$ and $\varepsilon$ is the surface emissivity. The emissivity had to be taken into account, this was assumed to be 0.99 because NDVI falls between the range of $(0.2<$ NDVI $>0.5)$ (Sobrino $e t$ al., 2004), hence, the fractional vegetation proportion (Pv) was not necessary to calculate.

$$
\varepsilon= \begin{cases}0.990 & (N D V I<0.2, N D V I>0.5) \\ 0.004 P v+0.986 & (0.2 \leq N D V I \leq 0.5)\end{cases}
$$

The NDVI, GNDVI, NDWI and NDMI spectral indices were computed from the reflectance images $\rho \lambda^{\prime}$ using IDL according to Table 1 .

\subsection{Statistical Analysis}

Least squares linear regression models were developed in R-Studio for the LST-vegetation index relationships. The LST was considered to be a dependent variable and the vegetation indices were considered to be independent variables. The coefficient of determination $\left(\mathrm{R}^{2}\right)$ was calculated to determine the fit of the linear models. The p-value was calculated to determine the significance of the relationships. The Root Mean Square Error (RMSE) evaluate the validity of the models. Thereafter, the scatterplots were made to understand the LST-vegetation index slope and the distribution of the sample points. 


\section{Results and Discussion}

\subsection{Spatial Variation of the LST-vegetation Index Relationships at a Farm Level}

The spatial distribution of LST and the vegetation indices for selected winter wheat farms are illustrated in Figure 2. The LST is low at vegetated wheat farms, whereas, the NDVI and GNDVI are high at these wheat farms, the opposite trend is observed for fallow or harvested farms. This observation is expected for wheat; healthy vegetation reflects more radiation in the near infrared section of the solar spectrum as compared to the visible section because this portion absorbs chlorophyll. Additionally, healthy vegetation emits less thermal radiation in the infrared section because of cooler transpiration from the canopy (Kogan et al., 2005).
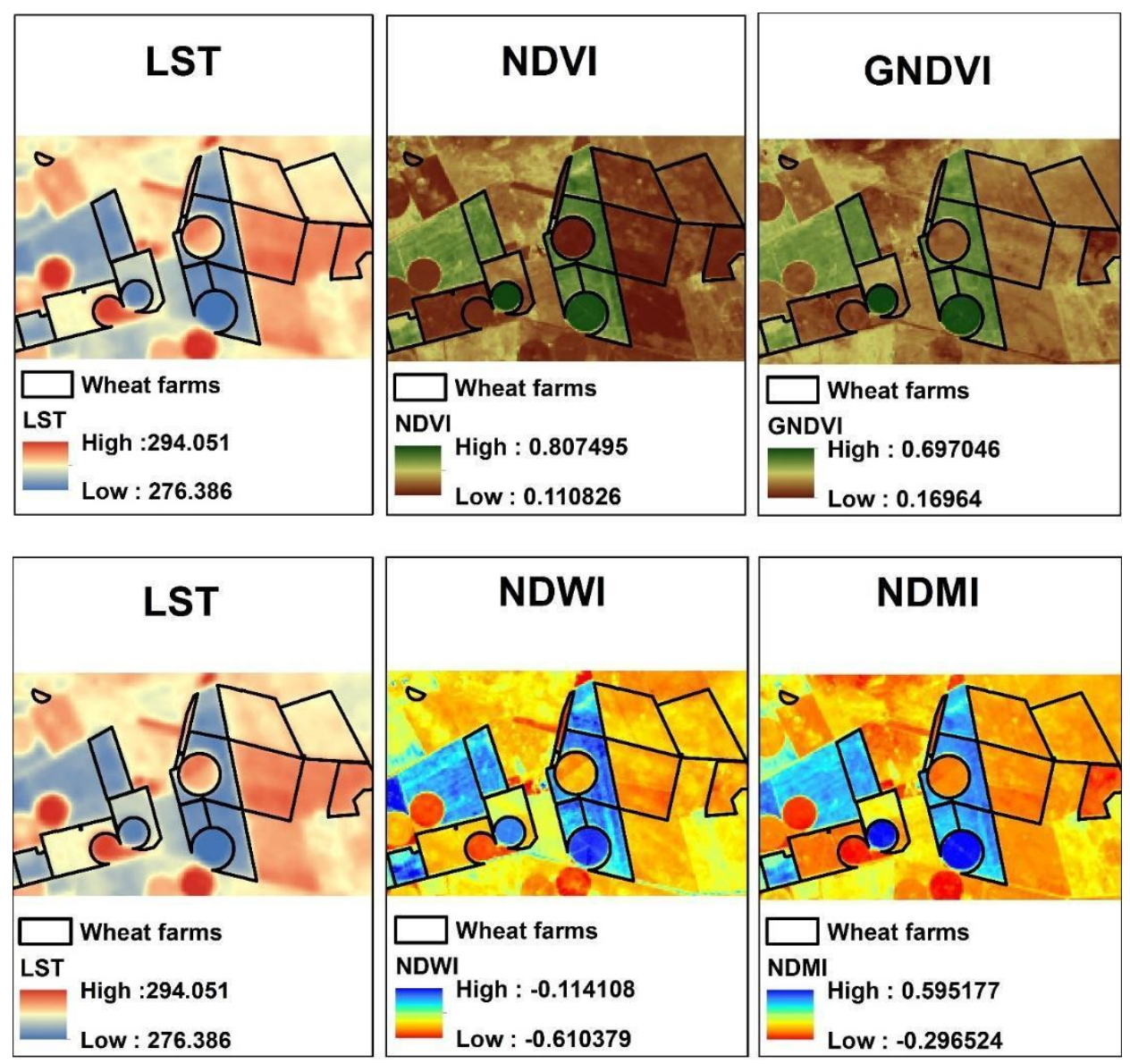

Figure 2. The performance of each vegetation index for winter wheat at a farm level against LST

(units are in Kelvin). The farms were selected as examples from the wheat farms in Figure 1. 
South African Journal of Geomatics, Vol. 5. No. 2, September 2016

The moisture indices are positively related to LST and indicate that wheat farms, which are flourishing have a high moisture content. Since Bloemfontein is characterised by summer rainfall, this could be indicative that these areas have a higher residual soil moisture during the winter season because of a high water table. These qualitative relationships were verified statistically.

\subsection{Statistical Analysis of the LST-vegetation Index Relationships}

The results of regression analysis between LST and vegetation indices are depicted in Table 3. Through the use of $\mathrm{R}^{2}$, moderate correlations were observed between LST and NDVI for the selected vegetation indices. The LST and NDWI exhibited a strong correlation for the selected moisture indices. The LST-GNDVI and LST-NDMI both had a moderate correlation. This indicated that the LST-NDVI relationship and the LST-NDWI relationship were better estimates of the wheat health status. The correlations were not the same over the years, this could be a result of changes in the soil conditions due to agricultural management practices and fluctuations in the weather patterns. Significance levels were calculated in order to determine the relationship between LST and the vegetation indices. Most of the derived linear relationships indicated a good level of significance with p-values less than 0.05 for all the years (Table 3). The RMSE values were lower in 2014 compared to 2013, this indicated improvements in the accuracy of the models.

The scatterplots in Figure 3 are for the winter wheat sample points displayed in Figure 1. The scatterplots indicate a decrease in the wheat health status from 2013 to 2014 because the values for LST and the spectral indices for the sample points decreased over these years. Steeper slopes on the LST-vegetation index plots are observed on periods of reduced soil moisture and vegetation amount (Goetz, 1997). The slope of the LST/vegetation index scatterplots were negative consistent with previous research. Nemani et al. (1993) observed a negative relationship between NDVI and LST for grasses, crops, and forests, and established that fractional canopy cover was an important variable in controlling surface temperatures. Hope (1988) observed a negative relationship when determining the actual canopy resistance for wheat by combining the remotely sensed spectral reflectance and land surface temperature. Weng et al. (2004) observed a negative relationship between cropland and land surface temperature. These relationships arise due to the cooling effects of canopy transpiration (Kogan et al., 2005). The use of the LST-vegetation relationships for crop health status monitoring described in this research can be used to replace the Crop Water Stress Index (CWSI), which is more computationally intensive as it requires the computation of the 
vegetation index-temperature trapezoid (Moran et al., 1994; Clarke, 1997). However, the disadvantage of using remotely sensed imagery is that they give an indication of the crops water status only during the time the image was taken, therefore, it is important to select an image at the critical growth stages. Overall, this research has proven that the LST-vegetation index relationships can be used for wheat health status monitoring and has determined the best indices which comprehensively describe wheat health.

Table 3. The LST-vegetation index regression models, coefficient of determination $\left(\mathrm{R}^{2}\right)$ and significance level for winter wheat

\begin{tabular}{lcllll}
\hline Relationship & Year & Regression Model & $\mathrm{R}^{2}$ & $\begin{array}{l}\text { Significance } \\
(\mathrm{p} \text {-value })\end{array}$ & $\begin{array}{l}\text { RMSE } \\
\left({ }^{\circ} \mathrm{C}\right)\end{array}$ \\
\hline LST-NDVI & 2013 & $\begin{array}{l}\text { LST=-8.890*NDVI+ } \\
289\end{array}$ & 0.3552 & 0.03160 & 1.4548 \\
& 2014 & $\begin{array}{l}\text { LST=-9.841*NDVI+ } \\
292\end{array}$ & 0.6200 & 0.00140 & 0.8617 \\
\hline LST-GNDVI & 2013 & $\begin{array}{l}\text { LST=-15.462*GNDVI+ } \\
293\end{array}$ & 0.2810 & 0.06238 & 1.5361 \\
& 2014 & $\begin{array}{l}\text { LST=-12.485*GNDVI+ } \\
294\end{array}$ & 0.4124 & 0.017195 & 1.0714 \\
\hline LST-NDWI & 2013 & $\begin{array}{l}\text { LST=-25.734*NDWI+ } \\
275\end{array}$ & 0.6502 & 0.00087 & 1.0715 \\
& 2014 & $\begin{array}{l}\text { LST=-19.110*NDWI+ } \\
281\end{array}$ & 0.8949 & 0.000001 & 0.4532 \\
\hline LST-NDMI & 2013 & $\begin{array}{l}\text { LST=-9.855*NDMI+ } \\
286 \\
\text { LST=-8.256*NDMI+ }\end{array}$ & 0.5269 & 0.00497 & 1.2461 \\
& 289 & 0.7916 & 0.00004 & 0.6381 \\
\hline
\end{tabular}



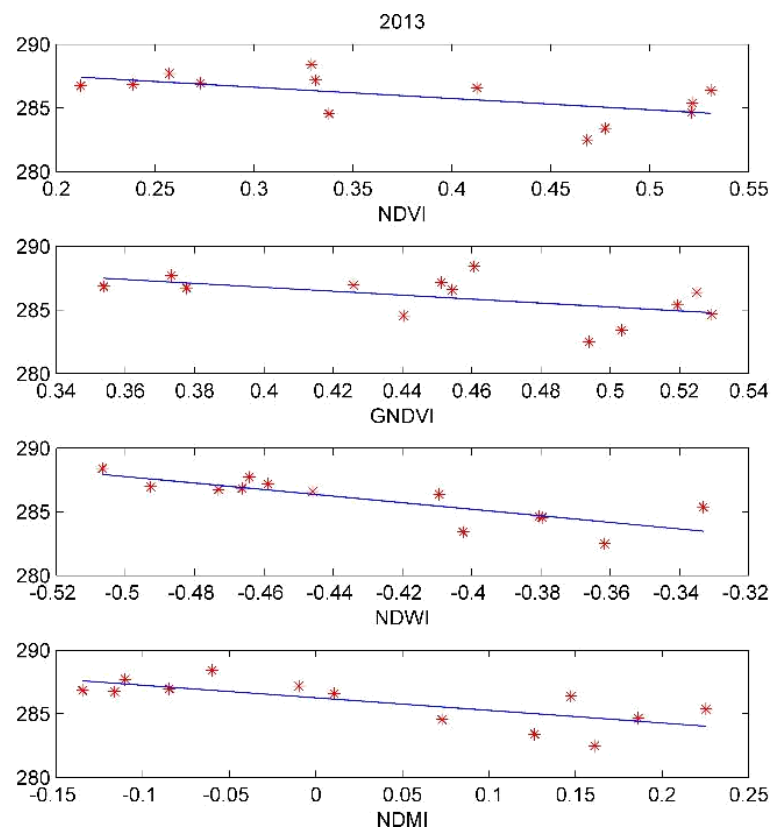
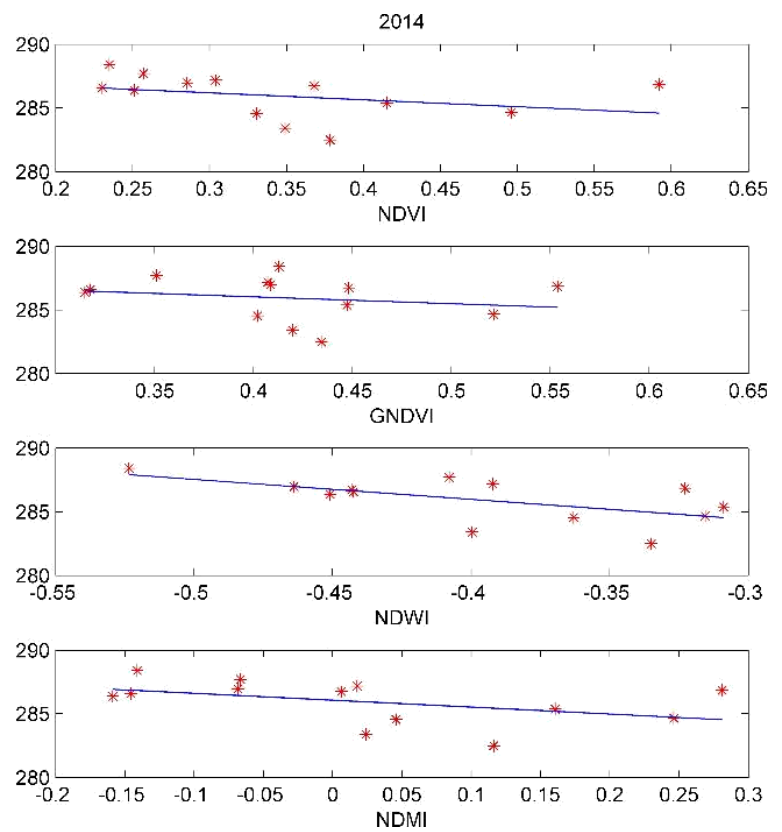

Figure 3. The LST-vegetation index scatter plots for 2013-2014 at the selected sample points (LST unit is Kelvin). The LST-vegetation index plots have negative relationships

\section{Conclusion}

This research was important because wheat is one of the staple crop for South Africa. With Landsat 8 derived remotely sensed data, the indices sensitive to changes in wheat health were identified. The LST has an inverse relationship with the vegetation abundance indices, this indicates that healthy wheat releases more transpiration as compared unhealthy wheat. Nemani et al., 1993 observed this negative trend for grasses, crops, and forests. Steeper slopes on the LSTvegetation index plots were observed on periods of reduced soil moisture and vegetation amounts consistent with the slope Goetz (1997) observed in mixed grassland sites. The NDVI and NDWI proved were suitable indices for monitoring the wheat health status as compared to the GNDVI and NDMI. A better fit was observed for the moisture indices as compared to the vegetation abundance indices. To improve these findings, more sample points can be added depending on how consistently farmer's plant wheat at the same areas. The performance of other vegetation indices can be compared with the ones used in this research. These pilot results indicate that the LST/vegetation index relationships can be applied to monitor wheat health status in the Bloemfontein area at the critical stages of growth. Through the use of the LST-vegetation index relationship, farmers can mitigate conditions hampering wheat growth such as a lack of moisture, fertiliser, pesticides or herbicides at stressed areas. 


\section{Acknowledgements}

The authors would like to thank the Agricultural Research Council for funding this research. The Centre for Geoinformation Sciences at the University of Pretoria for their continued support.

\section{References}

Abuzar, M, McAllister, A \& Morris, M 2000, 'Classification of seasonal images for monitoring irrigated crops in a salinity-affected area of Australia', International Journal of Remote Sensing, vol. 22, no. 5, pp. 717-726.

Artis, DA \& Carnahan, WH 1982, 'Survey of emissivity variability in thermography of urban areas', Remote Sensing of Environment, vol. 12, no. 4, pp. 313-329.

Breitenbach MC \& Fényes TI 2000, 'Maize and wheat production trends in South Africa in a deregulated environment', Agrekon, vol. 39, no. 3, pp. 292-312.

Chavez, PS \& MacKinnon, DJ 1994, 'Automatic detection of vegetation changes in the Southwestern United States using remotely sensed images', Photogrammetric Engineering and Remote Sensing, vol. 60, no. 5, pp. 571-583.

Clarke, TR 1997 'An empirical approach for detecting crop water stress using multispectral airborne sensors', HortTechnology, vol. 7, no. 1, pp. 9-16.

Clevers, JGPW \& Van Leeuwen, HJC 1996, 'Combined use of optical and microwave remote sensing data for crop growth monitoring', Remote Sensing of Environment, vol. 56, no. 1, pp. 42-51.

Combrink, AZ, Bos, MS, Fernandes, RM, Combrinck, WL \& Merry, CL 2007, 'On the importance of proper noise modelling for long-term precipitable water vapour trend estimations', South African Journal of Geology, vol. 110, no. 2-3, pp. 211-218.

Cohen, WB, Maiersperger, TK, Gower, ST \& Turner, DP 2003, 'An improved strategy for regression of biophysical variables and Landsat ETM+', Remote Sensing of Environment, vol. 84, no. 4, pp. 561-571.

Cooley, T, Anderson, GP, Felde, GW, Hoke, ML, Ratkowski, AJ, Chetwynd, JH, Gardner, JA, AdlerGolden, SM, Matthew, MW, Berk, A \& Bernstein, L 2002, 'FLAASH, a MODTRAN4-based atmospheric correction algorithm, its application and validation,' In Geoscience and Remote Sensing Symposium, 2002. IGARSS'02. 2002 IEEE International, vol. 3, pp. 1414-1418.

Doraiswamy, PC, Hatfield, JL, Jackson, TJ, Akhmedov, B, Prueger, J \& Stern, A 2004, 'Crop condition and yield simulations using Landsat and MODIS,' Remote Sensing of Environment, vol. 92, no. 4, pp. 548-559.

Elmore, AJ, Mustard, JF, Manning, SJ \& Lobell, DB 2000, 'Quantifying vegetation change in semiarid environments: precision and accuracy of spectral mixture analysis and the normalized difference vegetation index', Remote sensing of Environment, vol. 73, no. 1, pp. 87-102.

Gamon, JA, Field, CB, Goulden, ML, Griffin, KL, Hartley, AE, Joel, G, Peñuelas \& Valentini, R 1995 , 
'Relationships between NDVI, canopy structure and photosynthesis in three Californian vegetation types', Ecological Society of America, vol. 5, no. 1, pp. 28-41.

Gitelson, AA, Kaufman, YJ \& Merzlyak 1996, 'Use of green channel in remote sensing of global vegetation from EOS-MODIS', Remote Sensing of the Environment, vol. 58, no. 3, pp. 289-298.

Goetz, SJ 1997, 'Multi-sensor analysis of NDVI, surface temperature and biophysical variables at a mixed grassland site', International Journal of Remote Sensing, vol. 18, no. 1, pp. 71-94.

Guo, Z, Wang SD, Cheng, MM \& Shu, Y 2012, 'Assessing the effect of different degrees of urbanization on land surface temperature using remote sensing images', Procedia Environmental Sciences, vol. 13, pp. 935-942.

Hackl, M, Malservisi, R, Hugentobler, U \& Wonnacott, R 2011, 'Estimation of velocity uncertainties from GPS time series: Examples from the analysis of the South African TrigNet network', Journal of Geophysical Research: Solid Earth, vol. 116, no. B11.

Hardisky, MA, Klemas, V \& Smart, RM 1983, 'The influence of soil salinity, growth form and leaf moisture on the spectral radiance of Spartina alterniflora canopies', Photogrammetric Engineering and Remote Sensing, vol. 49, pp. 77-83.

Hoogenboom, G 2000, 'Contribution of agrometeorology to the simulation of crop production and its applications', Agricultural and forest meteorology, vol. 103, no. 1, pp. 137-157.

Hope, AS 1988, 'Estimation of wheat canopy resistance using combined remotely sensed spectral reflectance and thermal observations', Remote Sensing of Environment, vol. 24, no. 2, pp. 369-383.

Huete, AR, Liu, HQ, Batchily, K \& Van Leeuwen, WJDA 1997, 'A comparison of vegetation indices over a global set of TM images for EOS-MODIS', Remote Sensing of Environment, vol. 59, no. 3, pp. 440-451.

Jackson, TJ, Chen, D, Cosh, M, Li, F, Anderson, M, Walthall, C, Doriaswamy, P \& Hunt, ER 2004, 'Vegetation water content mapping using Landsat data derived normalized difference water index for corn and soybeans', Remote Sensing of Environment, vol. 92, no. 4, pp. 475-482.

Jiang, J \& Tian, G 2010, 'Analysis of the impact of Land use/Land cover change on Land Surface Temperature with Remote Sensing', Procedia Environmental Sciences, vol. 2, pp. 571-575.

Ji-hua, M \& Bing-fang, W 2008, 'Study on the crop condition monitoring methods with remote sensing', International Archives of the Photogrammetry, Remote Sensing and Spatial Information Sciences, vol. 37, no. B8, pp. 945-950.

Jin, S \& Sader, SA 2005, 'Comparison of time series tasseled cap wetness and the normalized difference moisture index in detecting forest disturbances', Remote Sensing of Environment, vol. 94, pp. 364-372.

Johnson, DM 2014, 'An assessment of pre-and within-season remotely sensed variables for forecasting corn and soybean yields in the United States', Remote Sensing of Environment, vol. 141, pp. 116128.

Julien, Y, Sobrino, JA \& Verhoef, W 2006, 'Changes in land surface temperatures and NDVI values over Europe between 1982 and 1999', Remote Sensing of Environment, vol. 103, no. 1, pp. 43-55. 
Julien, Y \& Sobrino, JA 2009, 'The Yearly Land Cover Dynamics (YLCD) method: An analysis of global vegetation from NDVI and LST parameters', Remote Sensing of Environment, vol. 113, no. 2, pp. 329-334.

Karnieli, A, Agam, N, Pinker, RT, Anderson, M, Imhoff, ML, Gutman, GG, Panov, N \& Goldberg, A 2010, 'Use of NDVI and land surface temperature for drought assessment: Merits and limitations', Journal of Climate, vol. 23, no. 3, pp. 618-633.

Kawabata, A, Ichii, K \& Yamaguchi, Y 2001, 'Global monitoring of interannual changes in vegetation activities using NDVI and its relationships to temperature and precipitation', International Journal of Remote Sensing, vol. 22, no. 7, pp. 1377-1382.

Kogan, F, Yang, B, Wei, G, Zhiyuan, P \& Xianfeng, J 2005, 'Modelling corn production in China using AVHRR-based vegetation health indices', International Journal of Remote Sensing, vol. 26, no. 11, pp. 2325-2336.

Kuenzer, C \& Knauer, K 2013, 'Remote sensing of rice crop areas', International Journal of Remote Sensing, vol. 34, no. 6, pp. 2101-2139.

Löw, F. \& Duveiller, G 2014, 'Defining the spatial resolution requirements for crop identification using optical remote sensing', Remote Sensing, vol. 6, no. 9, pp.9034-9063.

Meyer, F \& Kirsten, J 2005, 'Modelling the wheat sector in South Africa', Agrekon, vol. 44, no. 2, pp. 225-237.

McDonald, AJ, Gemmell, FM \& Lewis, PE, 'Investigation of the utility of spectral vegetation indices for determining information on coniferous forests', Remote Sensing of Environment, vol. 66, no. 3, pp. 250-272.

McFeeters, SK 1995, 'The use of normalized difference water index (NDWI) in the delineation of open water features', International Journal of Remote Sensing, vol. 17, no. 7, pp. 1425-1432.

Moeletsi, ME, Walker, S \& Landman, WA 2011, 'ENSO and implications on rainfall characteristics with reference to maize production in the Free State Province of South Africa', Physics and Chemistry of the Earth, vol. 36, no. 14, pp. 715-726.

Moges, SM, Raun, WR, Mullen, RW, Freeman, KW, Johnson, GV \& Solie, JB 2004, 'Evaluation of Green, Red, and Near Infrared Bands for Predicting Winter Wheat Biomass, Nitrogen Uptake, and Final Grain Yield', Journal of Plant Nutrition, vol. 27, no. 8, pp. 1431-1441.

Moran, MS, Clarke, TR, Inoue, Y \& Vidal, A 1994, 'Estimating crop water deficit using the relation between surface-air temperature and spectral vegetation index', Remote Sensing of Environment, vol. 49, no. 3, pp. 246-263.

Moulin, S, Bondeau, A \& Delecolle, R 1998, 'Combining agricultural crop models and satellite observations: from field to regional scales', International Journal of Remote Sensing, vol. 19, no. 6, pp. 1021-1036.

Nemani, R, Pierce, L, Running, S \& Goward, S 1993, 'Developing satellite-derived estimates of surface moisture status', Journal of Applied Meteorology, vol. 32, pp. 548-557. 
Parida, BR, Collado, WB, Borah, R, Hazarika, MK \& Samarakoon, L 2008, 'Detecting drought-prone areas of rice agriculture using a MODIS-derived soil moisture index', GIScience and Remote Sensing, vol. 45, no. 1, pp. 109-129.

Prihodko, L \& Goward, SN 1997, 'Estimation of air temperature from remotely sensed observations', Remote Sensing environment', vol. 60, no. 6, pp. 335-346.

Raynolds, MK, Comiso, JC, Walker, DA \& Verbyla, D 2008, 'Relationship between satellite-derived land surface temperatures, arctic vegetation types, and NDVI', Remote Sensing of Environment, vol. 112, no. 4 , pp. 1884-1894.

Sandholt, I, Rasmussen, K \& Andesrsen, J 2002, 'A simple interpretation of the surface temperature/vegetation index space for assessment of surface moisture status', Remote Sensing environment, vol. 79, no. 2, pp. 213-222.

Sobrino, JA, Jiménez-Muñoz, JC \& Paolini, L 2004, 'Land surface temperature retrieval from LANDSAT TM 5', Remote Sensing of Environment, vol. 90 no. 4, pp. 434-440.

Son, NT, Chen, CF, Chen, CR, Chang, LY \& Minh VQ 2012, 'Monitoring agricultural drought in the Lower Mekong Basin using MODIS NDVI and land surface temperature data', International Journal of Applied Earth Observation and Geoinformation, vol. 18, pp. 417-427.

Srivastava, PK, Han, D, Rico-Ramirez, MA, Bray, M, Islam, T, Gupta, M \& Dai, Q 2014, 'Estimation of land surface temperature from atmospherically corrected LANDSAT TM image using 6S and NCEP global reanalysis product', Environmental Earth Sciences, vol. 72, no. 12, pp. 5183-5196.

Swain, S, Wardlow, BD, Narumalani, S, Tadesse, T \& Callahan, K 2011, 'Assessment of vegetation response to drought in Nebraska using Terra-MODIS land surface temperature and normalized difference vegetation index', GIScience \& Remote Sensing, vol. 48, no. 3, pp.432-455.

Tadross, MA, Hewitson, BC \& Usman MT 2005, 'The interannual variability of the onset of the maize growing season over South Africa and Zimbabwe', Journal of climate, vol. 18, no. 16, pp. 33563372.

Weng, Q, Lu, D \& Schubring, J 2004, 'Estimation of land surface temperature-vegetation abundance relationship for urban heat island studies', Remote Sensing of Environment, vol. 89, no. 4, pp. 467483.

Wilson, EH \& Sader, SA 2002, 'Detection of forest harvest type using multiple dates of Landsat TM imagery', Remote Sensing of Environment, vol. 80, no. 3, pp. 385-396.

$\mathrm{Xu}, \mathrm{H}$ 2006, 'Modification of normalised difference water index (NDWI) to enhance open water features in remotely sensed imagery', International Journal of Remote Sensing, vol. 27, no. 14, pp. $3025-3033$. 